\title{
Food retailer practices, attitudes and beliefs about the supply of healthy foods
}

\author{
Tatiana Andreyeva*, Ann E Middleton, Michael W Long, Joerg Luedicke and \\ Marlene B Schwartz \\ Rudd Center for Food Policy and Obesity, Yale University, 309 Edwards Street, New Haven, CT 06520-8369, \\ USA
}

Submitted 16 August 2010: Accepted 9 January 2011: First published online 16 February 2011

\begin{abstract}
Objective: Non-supermarket food retailers can be a promising channel for increasing the availability of healthy foods in underserved communities. The present paper reports on retailer practices, attitudes and beliefs about the supply of healthy foods before and after the introduction of new subsidies for healthy foods by the US Special Supplemental Nutrition Program for Women, Infants, and Children (WIC) in October 2009.

Design: We designed and conducted in-person standardized interviews with store owners and managers to assess perceptions of demand and profits for different foods, supply networks, barriers to stocking healthy foods and their changes following implementation of the new WIC packages.

Setting: Non-supermarket retailers in five towns of Connecticut, USA ( $n 68$ in 2009 and $n 58$ in 2010).

Subjects: Owners and managers of WIC-authorized and non-WIC convenience stores and non-chain grocery stores.

Results: Retailers identified customer demand as the primary factor in stocking decisions. They reported observing a significantly weaker demand for healthy foods compared with unhealthy foods, although it improved for certain foods with the new WIC subsidies. Less healthy foods were also perceived as more profitable. Supplier networks varied by product from convenient manufacturer delivery for salty snacks to self-supply for produce. WIC retailers were able to quickly adapt and supply healthy foods required under the new WIC programme guidelines.

Conclusions: Retailers other than supermarkets currently perceive little demand for healthy foods, but new WIC subsidies have the power to change these perceptions. Supply barriers seem secondary in the limited offerings of healthy foods by stores and could be overcome when policy changes generate new demand for healthy foods.
\end{abstract}

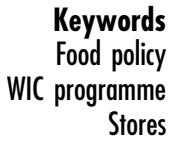

Stores
Residents in communities with limited availability of healthy foods are at higher risk for poor nutrition ${ }^{(1,2)}$ and chronic illnesses including obesity ${ }^{(3,4)}$ and heart disease $^{(5,6)}$. Low-income and minority populations in the USA are more likely to have limited supermarket access combined with saturation of fast-food establishments and convenience stores $^{(7,8)}$, a pattern that has not consistently been observed in other wealthy countries ${ }^{(9)}$. Although evidence is mixed ${ }^{(10-14)}$, poor food access conditions have been linked to lower fruit and vegetable intakes ${ }^{(15-17)}$ and higher risk of obesity in adults and adolescents ${ }^{(7,18-21)}$. Even when physical access to healthy foods is available, higher prices and poor quality may be meaningful barriers to improving nutrition and health in vulnerable populations in many countries ${ }^{(22-28)}$. Despite widespread findings of limited access to healthy foods in low-income communities $^{(2)}$, few studies have assessed the causes of this disparity. One hypothesis is that low demand for healthy foods discourages retailers from stocking them. Limited supply networks or inadequate storage capacity could also limit the ability of convenience stores and small groceries to supply healthier products despite increased demand. Anecdotal evidence and focus group reports suggest that retailers would provide healthy foods if they perceived demand for these products ${ }^{(29,30)}$.

Government food assistance programmes can play a role in increasing demand for healthy foods via economic incentives such as food subsidies and income transfers. Interventions in both developed and developing countries have used conditional cash and in-kind transfers to encourage purchases of healthy foods, with mixed results. For example, income transfers without concurrent 
promotion of healthy foods ${ }^{(28)}$ were shown to improve intakes of healthy foods but also increase consumption of unhealthy foods and thus contribute to excess energy intake $^{(31)}$. Recently, the US Special Supplemental Nutrition Program for Women, Infants, and Children (WIC) initiated changes designed to improve the diets of WIC participants through the provision of certain healthy foods ${ }^{(32)}$. WIC is one of the federal food assistance programmes that supplies low-income families with vouchers for specific food packages intended to support prenatal, infant and child development. WIC vouchers are redeemable only in authorized stores, which are required to stock certain WIC foods. Since October 2009, WIC participants began to receive vouchers for new food packages including fruit and vegetables, whole grains and other nutritious products. Given that the WIC programme spends over $\$$ US 4.6 billion annually on food packages for over nine million WIC recipients ${ }^{(33)}$, this policy change has the potential to create significant new demand for foods that were previously lacking or insufficient in the diets of low-income populations and in the stores that serve them.

The purpose of the present study was to understand the perceptions of demand for healthy foods, supply practices and barriers to stocking healthy foods, and the role of WIC revisions in the operation of convenience stores and non-chain grocery stores in the USA. We surveyed storeowners and managers before and after the implementation of the WIC revisions to assess changes in their practices and perceptions about selling various foods and identify whether retailers were able to overcome supply barriers in meeting new demand for healthy foods. Results from our study can inform the development and revisions of food assistance programmes in the USA and other countries responding simultaneously to food insecurity and the obesity epidemic, as well as contribute to broader efforts to reduce disparities in access to healthy foods.

\section{Methods}

\section{Sampling frame}

The retailer survey was part of a larger study assessing the effects of change in the federal WIC policy on the availability, quality and prices of healthy foods. In-store assessment of these factors relied on an updated version of a food environment measurement tool ${ }^{(22)}$ adapted from the Nutrition Environment Measures Survey in stores (NEMS-S) ${ }^{(22,34)}$. The larger study sample frame included all food retailers operating in five towns in Connecticut, USA. To maximize the diversity of food environments surveyed within a limited study budget, we sampled towns from the twenty-four most populated towns in Connecticut and selected five towns to represent communities from a broad range of residential income and food retailer densities. The retailer survey used a pre/post-matched, non-randomized design to select WIC and non-WIC food stores other than supermarket chains, such as convenience stores and independent (non-chain) groceries within the five towns.

\section{Selection of stores and data collection}

We obtained a list of food retailers in Connecticut from InfoUSA Inc., a commercial database provider ${ }^{(35)}$. Retailer locations were geocoded to identify stores within the five towns and within a half mile buffer around the official boundary of each town included in our sample using ArcGIS 9.2 (ESRI, Inc., Redlands, CA, USA) Census 2000 TIGER/Line ${ }^{\circledR}$ data ${ }^{(36)}$ (ESRI, Inc.) designated town and census tract boundaries and InfoUSA provided latitude and longitude coordinates for store locations. We verified and extended InfoUSA store locations on the basis of WIC administrative data and fieldwork. We recruited all WIC-authorized retailers other than supermarket chains operating within the study sampling area ( $n$ 40). WIC authorization status was assessed during store visits and verified in state administrative records. We then purposively sampled comparable non-WIC retailers to serve as a control group for the study. Control stores were matched on store type (a non-chain grocery store, convenience store or a food mart, i.e. a convenience store at a gas station ${ }^{(22)}$ ) and proximity to WIC retailers (usually within the same census tract). We expected a lower response rate from non-WIC retailers on the basis of experience conducting store inventories in the study area. To recruit a similar number of WIC and non-WIC retailers, we included fifty-one non-WIC stores.

We recruited storeowners or managers directly involved in ordering food products to participate in a 30-45 min interview. Each participant was offered monetary compensation and signed an informed consent form. One or two interviewers visited the store to interview participants at the scheduled time on store premises. The interviewer read survey questions to the retailer, made clarifications, displayed answer choices for multiple choice questions and filled in the paper-based survey. Baseline interviews were conducted in English or Spanish during April-July 2009, and follow-up interviews were conducted in May-July 2010. All materials were approved by the University Institutional Review Board.

\section{Survey development and measures}

Survey constructs were pooled from literature on cigarette retailer interventions ${ }^{(37)}$ and food retailer focus group guides, as well as from qualitative surveys and state WIC surveys ${ }^{(38,39)}$. Each construct was evaluated in light of its feasibility in a small store context and relevance to the WIC policy change. We chose a structured interview over more qualitative, open-ended questions to be able to assess changes in retailer responses following the policy revision. The instrument was pilot tested in three stores outside the sample. The authors can provide copies of the surveys 
upon request. Store characteristics, demographics, stocking behaviour and attitudes regarding WIC were assessed with closed and open-ended questions.

\section{Product selection, suppliers and pricing}

Retailers were asked to categorize each supplier for each food category as: (i) a general distributor (a wholesaler who delivers products from multiple brands); (ii) direct store delivery (a manufacturer and distributor of a specific brand); or (iii) self-supply (a retailer stocking at supermarkets or warehouse clubs). Our product selection was based on foods from the pre- and post-revision WIC food packages as a proxy for healthy foods. These included fruit and vegetables (fresh, frozen and canned), whole wheat/ grain bread, cereals, reduced, low-fat or skimmed milk (i.e. lower-fat milk), tofu, soya milk, infant formula and jarred baby foods. In addition, we assessed several non-WIC products that are widely available, nutritionally poor and common in US diets ${ }^{(40-44)}$, such as soda, salty snacks, candy and white flour bread. Participants were asked to select how they determine pricing from a list of options, such as by manufacturer's suggestion or neighbourhood competition.

\section{Perceived demand}

To assess retailers' perceived demand by product category, participants responded to a statement '[Product] sells well in my store' on a 6-point scale $(1=$ strongly disagree, $2=$ disagree, $3=$ somewhat disagree, $4=$ somewhat agree, $5=$ agree and $6=$ strongly agree) for eighteen food categories. We also asked all retailers about hypothetical demand for selected foods. If stores did not stock a certain food, they rated the demand they could have had if they had been selling it. Stores already stocking the item rated the likelihood that customers would purchase more of that product. To summarize demand for healthy and unhealthy foods, we averaged demand across products. Hypothetical demand was used if the store did not offer the product. Product categories with a high number in hypothetical demand or in which we found significant differences between actual and hypothetical demand were excluded. The summary measure of demand for healthy food included fresh fruit, canned fruit, canned vegetables, lower-fat milk and wholegrain cereal (mean $=4 \cdot 00$, SD $0 \cdot 85$, $\alpha=0.63)$. For unhealthy foods, we included retailers' assessments of demand for salty snacks and soda (mean $=5 \cdot 57$, SD 0.48, $\alpha=0 \cdot 68$ ). In 2010, retailers were asked to report whether and how purchases of unhealthy and healthy foods had changed.

\section{Perceived profitability}

To assess perceived profitability by product category, retailers were asked 'Generally speaking, how much profit do you make from selling [product]?' on a 5-point scale $(1=$ very little, $2=$ lower than average, $3=$ average, $4=$ above average and $5=$ best of all foods). We built a summary measure for perceived profitability of healthy and unhealthy foods. Healthy food profitability was calculated as an average of scores for fresh fruit, fresh vegetables and lower-fat milk in stores that sold at least one of these most-prevalent healthy products (mean $=$ $2 \cdot 59$, SD $0 \cdot 87, \alpha=0 \cdot 78$ ). The perceived profitability of unhealthy food was assessed by averaging the scores for salty snacks, soda and candy when all three products were stocked (mean $=3 \cdot 44$ SD 0.82, $\alpha=0 \cdot 76)$.

\section{Healtby food attitudes, supports and barriers}

Attitudes about selling healthy food were assessed on the basis of retailers' ratings on the above-mentioned 6-point scale that: (i) the food they sold was healthy; (ii) they should play a role in increasing the availability of healthy food in the store neighbourhood; and (iii) if they stocked healthy food, their customers would have a better diet. We also asked retailers to consider: (i) whether their sales would go down if they stocked healthier foods; and (ii) whether their customers looked for healthier food in stores. Open-ended questions assessed interest in offering more healthy foods and strategies to increase sales of healthy foods. Supports and barriers to offering more healthy foods were assessed, including seven positive factors such as high profitability and eleven barriers such as lack of suppliers and limited customer demand. Respondents could also offer unlisted supports/barriers. In addition, retailers rated twelve strategies that government or non-profit organizations could use to support store provision of healthier foods, including training, tax incentives, customer education and changes to government programmes.

\section{Retailer perceptions of WIC programme and policy changes}

In 2009, all retailers were assessed on their knowledge of new WIC foods, expected changes in WIC participation due to programme revisions, feasibility of accommodating new foods (enough shelf space, refrigeration capacity) and expected business impact of the WIC policy change to add more healthy items to WIC packages. WIC retailers answered additional questions regarding impressions of the WIC programme. In 2010, WIC retailers were asked about changes they made to business practices to accommodate the new WIC foods. WIC stores also reported on challenges in implementation and overall effects of the WIC revisions on their business.

Empirical analyses were based on frequencies and mean comparisons using both single items and mean scales. Differences in means were tested with the (two-sided) $t$ test.

\section{Results}

\section{Response rate and sample description}

Sixty-eight of ninety-one retailers approached (75\%) participated in the baseline survey, with higher participation 
Table 1 Supply methods for food categories, 2009

\begin{tabular}{lccc}
\hline & \multicolumn{3}{c}{ Percentage of stores delivering product using } \\
\cline { 2 - 4 } Food categories & & General distributort & Direct store delivery \\
\hline WIC foods & 37 & 78 & 2 \\
Canned fruit and vegetables & 15 & 54 & 35 \\
Milk (any fat content) & 40 & 72 & 2 \\
Cereal & 19 & 42 & 50 \\
Bread & 46 & 72 & 2 \\
Formula & 37 & 71 & 0 \\
Baby food & 78 & 25 & 0 \\
Fresh fruit and vegetables & 33 & 76 & 0 \\
Frozen fruit and vegetables & 0 & 100 & 0 \\
Tofu & & & 4 \\
Standard (non-WIC) products & 50 & 66 & 77 \\
Candy & 12 & 32 & 35 \\
Salty snack & 28 & 59 & \\
Soda & & & \\
\hline
\end{tabular}

WIC, Special Supplemental Nutrition Program for Women, Infants, and Children.

Respondents could choose more than one response.

${ }^{*}$ A retailer stocks products from supermarkets or warehouses.

tDistributor or wholesaler who delivers products from multiple brands.

$\ddagger$ Manufacturer and distributor of a specific brand who also stocks products in the store.

rate among WIC (88\%) than among non-WIC retailers (65\%). Among participants in the baseline survey, most owned or managed convenience stores ( $75 \%$ ), with the remainder from non-chain grocery stores $(13 \%)$ and food marts (12\%). A total of $60 \%$ of the stores were in census tracts with a 2000 median household income below $185 \%$ of the US federal poverty level, which we chose to describe low-income communities (specifically, income below \$US 39200$)^{(45)}$. Only one-third of the respondents lived in the neighbourhood where they worked. The primary racial/ethnicities were South Asian (38\%) and Latino (38\%). Most interviews were conducted in English (78\%), yet only $21 \%$ of the respondents were native English speakers.

Interviews in 2010 were completed among fifty-eight of the sixty-eight baseline participants. More WIC stores were lost to follow-up compared with non-WIC stores in 2010, with some stores losing WIC authorization due to ownership changes or programme violations unrelated to the revisions. Several businesses have closed since the 2009 interviews. The final response rate for all stores participating in the 2-year survey assessment was $64 \%$. The same individuals were interviewed in both years in $85 \%$ of the stores.

\section{Product selection, suppliers and pricing}

Retailers reported customer requests as the primary factor in deciding which products to stock $(81 \%$ mentioned it as the main factor), with some also selecting profitability, supplier recommendations and wholesale deals (20-30\%). Close to half of the retailers were interested in offering new products and $83 \%$ were interested in selling healthy foods. Adding variety was mentioned as the motivation to offer new healthy foods. Customers' dislike and supermarket competition were cited as reasons for lack of interest.
Retailers reported using a range of suppliers that varied considerably across products (Table 1). Unhealthy foods such as salty snacks and soda were more likely to be delivered directly to stores and often shelved by the manufacturer, whereas healthy products (e.g. fresh, frozen and canned produce) were more likely to be self-stocked or obtained from a general distributor. Over half of the retailers (58\%) used manufacturer's/distributor's suggestions to set prices, whereas alternative strategies were neighbourhood price matching and flat markups (e.g. 30\% on all products).

\section{Perceived demand}

At both baseline and follow-up, retailers perceived lower customer demand for healthy $v$. unhealthy foods, both in comparing individual items and in summary scales (baseline paired $t(67)=-13.92, P<0 \cdot 001$ ). At baseline, there was no difference in perceived demand by WIC status except for infant formula, which was higher in WIC stores (baseline $t(55)=-2.53, P<0.05$ ). Almost all retailers said that whole milk, salty snacks and soda sold well, but less than half to one-third had the same opinion regarding many of the healthy items (Table 2). For some food categories, retailer ratings of customer demand differed for the healthier and unhealthy versions. For example, $42 \%$ of baseline respondents thought that wholegrain cereals were selling well; however, for cereals high in sugar, responses were more positive: $71 \%$ of retailers thought that they sold well. The difference in perceived demand across types of milk was even greater: $37 \%$ of 2009 demand ratings were positive for lower-fat milk $v .93 \%$ for whole milk. This reduced in 2010 when positive rankings of lower-fat milk went up to $49 \%$. At follow-up, many WIC store retailers reported increased demand for certain healthy foods, including fresh fruit 
Table 2 Perceived demand and profitability across foods

\begin{tabular}{|c|c|c|c|c|c|c|c|c|}
\hline \multirow[b]{3}{*}{ Food categories } & \multirow{2}{*}{\multicolumn{2}{|c|}{$\begin{array}{l}\text { Percentage of retailers } \\
\text { who agree or strongly } \\
\text { agree that 'product sells } \\
\text { well in my store' }\end{array}$}} & \multicolumn{4}{|c|}{$\begin{array}{l}\text { Percentage of retailers reporting increases or } \\
\text { decreases in demand between } 2009 \text { and } 2010\end{array}$} & \multirow{2}{*}{\multicolumn{2}{|c|}{$\begin{array}{c}\text { Percentage of retailers } \\
\text { reporting above average } \\
\text { or best of all profits from } \\
\text { selling the product }\end{array}$}} \\
\hline & & & \multicolumn{2}{|c|}{ Increase } & \multicolumn{2}{|c|}{ Decrease } & & \\
\hline & 2009 & 2010 & WIC store & Non-WIC store & WIC store & Non-WIC store & 2009 & 2010 \\
\hline Soda & 98 & 98 & 15 & 19 & 6 & 4 & 60 & 67 \\
\hline Salty snacks & 95 & 93 & 15 & 19 & 10 & 0 & 32 & 41 \\
\hline Whole milk & 93 & 97 & 7 & 6 & 13 & 37 & 43 & 48 \\
\hline White bread & 86 & 93 & 11 & 6 & 6 & 4 & 29 & 32 \\
\hline Children's cereal & 71 & 74 & $-^{*}$ & $-^{*}$ & $-^{*}$ & $-^{*}$ & 33 & 37 \\
\hline Fresh vegetables & 63 & 43 & 48 & 6 & 3 & 7 & 18 & 21 \\
\hline Infant formula & 57 & 63 & 7 & 3 & 6 & 11 & 18 & 27 \\
\hline Wholegrain bread & 53 & 66 & 70 & 6 & 6 & 4 & 14 & 26 \\
\hline Canned vegetables & 52 & 47 & 22 & 3 & 13 & 4 & 16 & 21 \\
\hline Jarred baby food & 45 & 57 & 37 & 3 & 10 & 4 & 4 & 17 \\
\hline Fresh fruit & 43 & 57 & 74 & 10 & 0 & 8 & 14 & 11 \\
\hline Frozen fruit & 43 & 23 & 4 & 0 & 0 & 0 & 13 & 31 \\
\hline Wholegrain cereal & 42 & 47 & 33 & 0 & 6 & 7 & 12 & 32 \\
\hline Frozen vegetables & 41 & 32 & 7 & 3 & 3 & 0 & 35 & 5 \\
\hline $\begin{array}{l}\text { Lower-fat milk } \\
\qquad(2 \%, 1 \%, \text { skim })\end{array}$ & 37 & 49 & 63 & 16 & 10 & 4 & 14 & 22 \\
\hline Canned fruit & 37 & 41 & 30 & 0 & 13 & 4 & 16 & 21 \\
\hline Candy & $-{ }^{*}$ & $-{ }^{*}$ & 11 & 10 & 13 & 0 & 52 & 53 \\
\hline
\end{tabular}

WIC, Special Supplemental Nutrition Program for Women, Infants, and Children. Fifty-eight stores participated in both baseline and follow-up interviews.

${ }^{*}$ Not assessed.

and vegetables, wholegrain bread and cereal and lowerfat milk (Table 2). At the same time, they reported declines for products that were reduced in the new WIC food packages, such as whole milk.

\section{Perceived profitability}

At both baseline and follow-up, participants rated perceived profitability of all food items within a narrow range by citing that most products earned below average or average profit. Nevertheless, many reported making above average or their best profit from selling soda, candy and whole milk (Table 2). As with perceived demand, retailers rated profitability of healthier foods less favourably than their less healthy counterparts. For example, $14 \%$ of retailers said that they made at least above average profit on lower-fat milk $v .43 \%$ for whole milk in 2009. At baseline, perceived profitability of selling healthier foods was significantly lower than that of unhealthy foods on the basis of scale comparisons (paired $t(63)=$ $-6 \cdot 28, P<0 \cdot 001)$. Except for a higher perceived profitability of infant formula in WIC stores $(t(55)=-2 \cdot 09$, $P<0 \cdot 05)$, there was no significant difference in perceived profitability by WIC status at baseline and follow-up.

\section{Healtby food attitudes, supports and barriers}

At baseline, over half of the retailers agreed/strongly agreed that on average they sold healthy food in their stores; that they should play a role in increasing the availability of healthy food in their neighbourhood; and that if they stocked healthier food, their customers would have better diets. Attitudes towards offering healthy foods increased between 2009 and 2010 among WIC stores but worsened in non-WIC stores, although neither change was significant. Customer dislike was cited most frequently (31\%) as the primary barrier to stocking healthy foods. Spoilage was a common barrier to offering fresh fruit and vegetables, compared with refrigeration for frozen vegetables, customer dislike for whole grains and lower-fat milk, and no barriers for canned produce (Table 3). Finding a supplier and ordering small quantities were infrequently cited as important barriers. Customer dislike discouraged some retailers from offering wholegrain breads/cereals and lower-fat milk. The three potential institutional supports deemed most useful for the interviewed stores included monetary incentives to cover the cost of electricity $(74 \%$ found very useful), subsidies for healthy foods (73\%) and educating customers about healthy eating (63\%).

\section{Retailer perceptions of WIC programme and policy changes}

At baseline, most retailers (71\%) were happy or very happy to participate in the WIC programme. Advantages to participating in WIC included additional sales, customer traffic, financial stability in economic downturns and spillovers into non-WIC products. Disadvantages were extra time in processing WIC purchases, WIC customers 'trying to negotiate trades' for non-WIC products, price ceilings, minimum stocking requirements and punishment of the store for unauthorized purchases. As one respondent said, '[Customers] get angry when WIC rules are enforced, and will go to another store to get their products if you do not make illegal transactions'. Two-thirds of 


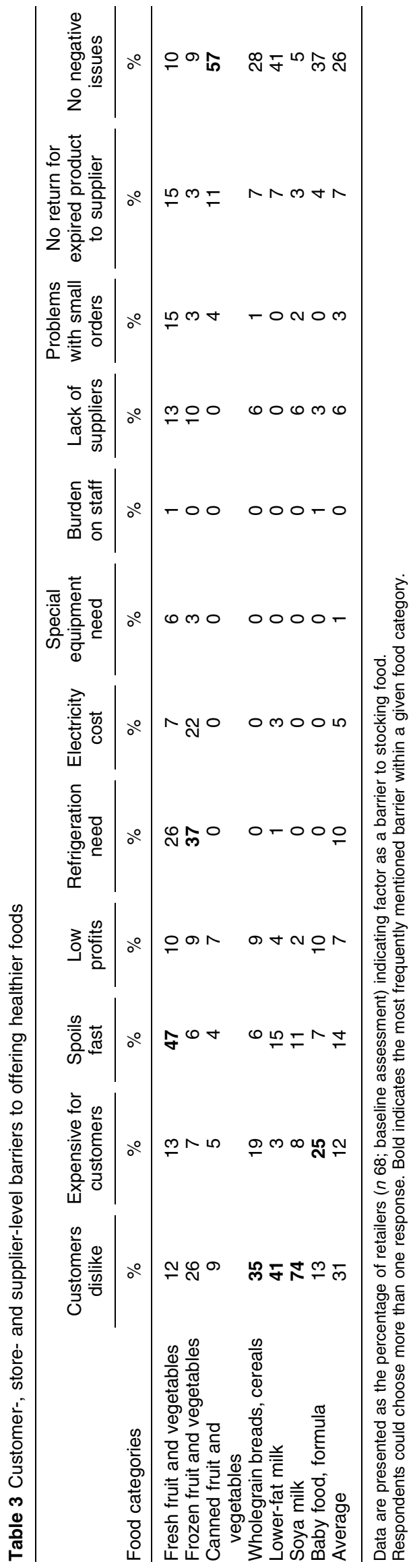

non-WIC stores had participated in WIC earlier. Some lost their authorization because of ownership changes or violations; others ended participation because of cumbersome paperwork. Half of the non-WIC stores had applied and been rejected WIC authorization (often because of state limits on the number of authorized stores in a certain area). Three-quarters were still interested in becoming authorized.

At baseline, almost all WIC retailers reported having enough shelf space (94\%), refrigeration (89\%) and suppliers (79\%) to accommodate the new foods. Most non-WIC retailers thought that they would be ready to accommodate the new products if they had to do so. Most stores felt that the change would be easy or very easy to incorporate (71\% WIC and 87\% non-WIC). At follow-up, WIC stores reported making multiple changes to accommodate the new packages, such as adding new products (93\%), increasing delivery frequency (54\%), training staff (54\%), increasing the amount of space allocated for WIC products (43\%) and purchasing new equipment (18\%). Most retailers had either a positive (46\%) or neutral (36\%) overall impression of the WIC programme changes, compared with $18 \%$ who had a negative overall impression.

\section{Discussion}

Our study adds important new information to policy makers regarding the potential impact of improved food assistance programme guidelines on community-level demand for healthy foods. Before recent WIC revisions, convenience stores and non-chain groceries in the state of Connecticut perceived limited demand for healthy foods in their stores, especially in comparison with demand for soda, candy and chips. Retailers consistently cited customer demand as the most important determinant of retailer stocking decisions. The addition of healthier food items to the WIC food packages in 2009 led to increases in perceived demand for certain healthy foods in stores authorized to accept WIC benefits compared with non-WIC stores. WIC participant demand for healthy products in the new WIC packages may persist after their WIC eligibility ends if participants develop taste preferences for healthier foods. Longterm assessment of changes in customer preferences, food choices and purchases is necessary to understand whether and how such changes occur.

Although customer demand has a powerful influence on retailer decisions to stock certain foods, the availability of suppliers is also important. Suppliers have pervasive influence in the market, particularly through price setting, which was mentioned by many retailers. Supplier networks differ by product, and healthy products such as fruits and vegetables typically have fewer suppliers. Produce is usually procured by small retailers through self-supply from supermarkets and warehouse clubs, potentially leading to double retail markup, poor food 
safety and increased spoilage due to multiple handling. In contrast, convenient delivery of chips and soda directly to stores makes it easy for retailers to stock them. Small retailers need distributors who will provide produce and other healthy foods in appropriate quantities and through convenient delivery mechanisms. This would likely increase the availability and quality of healthy foods and potentially reduce prices. Despite limitations in smallstore supplier networks, almost all (93\%) WIC-certified retailers reported adding new products in response to the WIC revisions, and few identified supplier networks as an important barrier or added a new supplier to comply with programme changes (18\%).

Before programme changes, WIC retailers anticipated few problems with implementation of the WIC food package revisions. Most felt that they could find suppliers, additional shelf space or equipment to provide the new products. Follow-up interviews confirmed that most retailers were able to accommodate new healthy foods in the revised WIC food packages, although retailers put extra effort and sometimes investment to meet new programme demands.

Our data represent food retailers other than supermarkets that operate in the state of Connecticut and may not generalize to other settings, particularly in developing countries with more limited supply networks. In the USA, rural areas might have unique challenges not captured in our study of urban and suburban neighbourhoods ${ }^{(32)}$. Assessing bigger samples of retailers from diverse locations would further help understand the perceptions, attitudes and business practices among owners and managers of convenience and non-chain grocery stores that in some neighbourhoods provide the only source of food access to community residents. Given the nature of personal interviews $^{(46)}$, some respondents probably gave socially desirable answers in our survey. For example, many retailers rated foods sold in their stores as healthy although in fact they had much greater offerings of unhealthy foods. It is also possible that monetary compensation for survey participation influenced some retailers, although we found no difference in the types of foods available between stores that agreed to participate and those that did not.

In conclusion, we designed a survey of non-chain supermarket food retailers to assess retailer practices, attitudes and beliefs around the supply of healthy foods. Our assessment suggests that convenience stores and non-chain groceries currently perceive little demand for healthy foods, but new WIC subsidies have the power to change that, at least in WIC-authorized stores. Supply barriers seem secondary in stores' limited offerings of healthy foods and could be overcome when policy changes generate new demand for healthy foods. This became evident following implementation of the revised WIC food packages that increased the types and amounts of major healthy foods (fruits and vegetables and wholegrain products) in WIC-authorized stores through stocking requirements while simultaneously subsidizing these foods for low-income women, children and infants. Revisions to food assistance programmes that increase demand for healthy foods have the potential to significantly improve the food environment in underserved communities with little burden on retailers.

\section{Acknowledgements}

The present study was funded by a grant from the US Department of Agriculture (USDA), Economic Research Service. The authors have no conflict of interest to declare. T.A. and M.W.L. developed the basic idea for the present study; T.A. and A.E.M. conducted the study; A.E.M. and J.L. were responsible for the statistical analyses of the results; T.A. and M.B.S. supervised all stages of the study. All co-authors participated in the interpretation of the study and in the preparation of the final manuscript. The authors thank Elizabeth Frazao and Phillip Kaufman (USDA) for comments on the survey and manuscript. They also acknowledge helpful comments from two anonymous referees and Joel Gittelsohn on the 2009 survey.

\section{References}

1. Booth SL, Sallis JF, Ritenbaugh C et al. (2001) Environmental and societal factors affect food choice and physical activity: rationale, influences, and leverage points. Nutr Rev 59, Suppl. 3, S21-S65.

2. Lovasi GS, Hutson MA, Guerra M et al. (2009) Built environments and obesity in disadvantaged populations. Epidemiol Rev 31, 7-20.

3. Larson NI, Story MT \& Nelson MC (2009) Neighborhood environments: disparities in access to healthy foods in the US. Am J Prev Med 36, 74-81.

4. Robert SA \& Reither EN (2004) A multilevel analysis of race, community disadvantage, and body mass index among adults in the US. Soc Sci Med 59, 2421-2434.

5. Diez Roux AV (2003) Residential environments and cardiovascular risk. J Urban Health 80, 569-589.

6. Diez Roux AV, Merkin SS, Arnett D et al. (2001) Neighborhood of residence and incidence of coronary heart disease. $N$ Engl J Med 345, 99-106.

7. Powell LM, Slater S, Mirtcheva D et al. (2007) Food store availability and neighborhood characteristics in the United States. Prev Med 44, 189-195.

8. Small ML \& McDermott M (2006) The presence of organizational resources in poor urban neighborhoods: an analysis of average and contextual effects. Soc Forces 84, 1697-1724.

9. Beaulac J, Kristjansson E \& Cummins S (2009) A systematic review of food deserts, 1966-2007. Prev Chronic Dis 6, A105.

10. Laska MN, Hearst MO, Forsyth A et al. (2010) Neighbourhood food environments: are they associated with adolescent dietary intake, food purchases and weight status? Public Health Nutr 13, 1757-1763.

11. Ford PB \& Dzewaltowski DA (2010) Limited supermarket availability is not associated with obesity risk among participants in the Kansas WIC Program. Obesity 18, 1944-1951.

12. Pearson T, Russell J, Campbell MJ et al. (2005) Do 'food deserts' influence fruit and vegetable consumption? - a cross-sectional study. Appetite 45, 195-197. 
13. Winkler E, Turrell G \& Patterson C (2006) Does living in a disadvantaged area entail limited opportunities to purchase fresh fruit and vegetables in terms of price, availability, and variety? Findings from the Brisbane Food Study. Health Place 12, 741-748.

14. Giskes K, van Lenthe FJ, Kamphuis CBM et al. (2009) Household and food shopping environments: do they play a role in socioeconomic inequalities in fruit and vegetable consumption? A multilevel study among Dutch adults. J Epidemiol Community Health 63, 113-120.

15. Rose D \& Richards R (2004) Food store access and household fruit and vegetable use among participants in the US Food Stamp Program. Public Health Nutr 7, 1081-1088.

16. Zenk SN, Schulz AJ \& Odoms-Young AM (2009) How neighborhood environments contribute to obesity. Am J Nurs 109, 61-64.

17. Timperio A, Ball K, Roberts R et al. (2008) Children's fruit and vegetable intake: associations with the neighbourhood food environment. Prev Med 46, 331-335.

18. Morland K, Diez Roux AV \& Wing S (2006) Supermarkets, other food stores, and obesity: the Atherosclerosis Risk in Communities Study. Am J Prev Med 30, 333-339.

19. Jago R, Baranowski T \& Baranowski JC (2007) Fruit and vegetable availability: a micro environmental mediating variable? Public Health Nutr 10, 681-689.

20. Zenk SN, Lachance LL, Schulz AJ et al. (2009) Neighborhood retail food environment and fruit and vegetable intake in a multiethnic urban population. Am J Health Promot 23, 255-264.

21. Zenk SN, Schulz AJ, Hollis-Neely T et al. (2005) Fruit and vegetable intake in African Americans income and store characteristics. Am J Prev Med 29, 1-9.

22. Andreyeva T, Blumenthal DM, Schwartz MB et al. (2008) Availability and prices of foods across stores and neighborhoods: the case of New Haven, Connecticut. Health Aff (Millwood) 27, 1381-1388.

23. Block D \& Kouba J (2006) A comparison of the availability and affordability of a market basket in two communities in the Chicago area. Public Health Nutr 9, 837-845.

24. Cummins S, Smith DM, Aitken Z et al. (2010) Neighbourhood deprivation and the price and availability of fruit and vegetables in Scotland. J Hum Nutr Diet 23, 494-501.

25. Cummins S, Smith DM, Taylor M et al. (2009) Variations in fresh fruit and vegetable quality by store type, urban-rural setting and neighbourhood deprivation in Scotland. Public Health Nutr 12, 2044-2050.

26. Hamelin A, Beaudry M \& Habicht J (2002) Characterization of household food insecurity in Quebec: food and feelings. Soc Sci Med 54, 119-132.

27. Jetter K \& Cassady D (2006) The availability and cost of healthier food alternatives. Am J Prev Med 30, 38-44.

28. Waterlander W, de Mul A, Schuit A et al. (2010) Perceptions on the use of pricing strategies to stimulate healthy eating among residents of deprived neighbourhoods: a focus group study. Int J Behav Nutr Phys Act 7, 44.

29. Gittelsohn J, Dyckman W, Tan ML et al. (2006) Development and implementation of a food store-based intervention to improve diet in the Republic of the Marshall Islands. Health Promot Pract 7, 396-405.
30. Pavlovich W (2004) Community-based participatory research and Baltimore Healthy Stores: goals, progress and future steps. Dissertation, Johns Hopkins Bloomberg School of Public Health.

31. de Bem Lignani J, Sichieri R, Burlandy L et al. (2010) Changes in food consumption among the Programa Bolsa Família participant families in Brazil. Public Health Nutr (Epublication ahead of print version).

32. Oliveira V \& Frazao E (2009) The WIC Program: Background, Trends, and Economic Issues. Economic Research Report no. 73. Washington, DC: USDA/ERS; available at http://www.ers.usda.gov/Publications/ERR73/ERR73Fm.pdf

33. US Department of Agriculture (2010) WIC program data: national level participation by category and costs. http:// www.fns.usda.gov/pd/37WIC_Monthly.htm

34. Glanz K, Sallis JF, Saelens BE et al. (2007) Nutrition Environment Measures Survey in stores (NEMS-S): development and evaluation. Am J Prev Med 32, 282-289.

35. InfoUSA, Inc. (2008) Database of US Businesses, vol. 2008. Omaha, NE: InfoUSA, Inc.

36. Environmental Systems Research Institute, Inc. (2000) US Census 2000 TIGER/Line Shapefile Data. Redlands, CA: ESRI, Inc.; available at http://arcdata.esri.com/data/tiger2000/ tiger_download.cfm

37. Woodruff SI, Erickson AD, Wildey MB et al. (1993) Changing retailer knowledge, attitudes, and behaviors related to cigarette sales to minors. J Community Psychol 21, 234-245.

38. Gittelsohn J, Franceschini MCT, Rasooly IR et al. (2008) Understanding the food environment in a low-income urban setting: implications for food store interventions. J Hunger Environ Nutr 2, 33-50.

39. New York State Health Department (2008) Vendor survey. In New York State WIC Program 2006 Vegetable and Fruit Demonstration Project. http://www.nyhealth.gov/ prevention/nutrition/wic/docs/vegetable_fruit_demo_project.pdf (accessed January 2009).

40. Piernas C \& Popkin BM (2009) Snacking increased among United States adults between 1977 and 2006. J Nutr 140, 325-332.

41. Piernas C \& Popkin BM (2010) Trends in snacking among US children. Health Aff (Millwood) 29, 398-404.

42. Popkin BM (2009) Global changes in diet and activity patterns as drivers of the nutrition transition. In Emerging Societies - Coexistence of Childbood Malnutrition and Obesity. Nestlé Nutrition Workshop Series. Pediatric Programme, vol. 63, 1-14 [SC Kalhan, AM Prentice and CS Yajnik, editors]. Vevey: S. Karger AG.

43. Wang MC, Cubbin C, Ahn D et al. (2008) Changes in neighbourhood food store environment, food behaviour and body mass index, 1981-1990. Public Health Nutr 11, 963-970.

44. French SA, Story M \& Jeffery RW (2001) Environmental influences on eating and physical activity. Annu Rev Public Health 22, 309-335.

45. Poverty Income Guidelines: Annual Update (2000) Federal Register 65 (February 15, 2000): 7555-7557.

46. Richman WL, Kiesler S, Weisband S et al. (1999) A metaanalytic study of social desirability distortion in computeradministered questionnaires, traditional questionnaires, and interviews. J Appl Psychol 84, 754-775. 